\title{
"Erro" no apoio ao Golpe de 64: sujeitos enfrentam-se nesse acontecimento discursivo
}

\author{
"Mistake" on supporting the 64 Coup d'état: subjects face off in this \\ discursive event \\ Belmira Magalhães \\ Universidade Federal de Alagoas, Maceió, AL, Brasil \\ Helson Flávio da Silva Sobrinho \\ Universidade Federal de Alagoas, Maceió, AL, Brasil
}

Resumo: Este artigo analisa o discurso e as condições sócio-históricas que levaram o sujeito, Organizações Globo, a declarar o "reconhecimento do erro" em ter "apoiado" o Golpe Militar de 1964, no Brasil. A pesquisa é filiada à Análise do Discurso (AD) e também toma o materialismo histórico-dialético para fundamentar os estudos sobre a categoria Totalidade. Como resultado, compreende-se que o acontecimento discursivo, produzido pela grande mídia, inscreve-se, a partir de determinado gesto de interpretação da memória histórica (Golpe, Revolução, Democracia), em uma região do dizível, para reafirmar sua posição política dominante na lógica capitalista da sociedade brasileira.

Palavras-chave: Sujeito. Discurso. História. Acontecimento.

Abstract: This paper analyses the discourse, as well as the social and historical conditions which led the subject, Organizações Globo, to declare the "admission of the mistake" of having "supported" the 1964 Brazilian Coup d'état. This research is affiliated to the French school of Discourse Analysis (DA), and takes the historical-dialectical materialism as the foundation of the study, under the Totality category. As a result, we understand that such a discursive event, produced by mainstream media, is inscribed, starting from a certain gesture of interpretation of historic memory (Coup d'état, Revolution, Democracy), in a region of what is sayable, in order to reassert its dominant political position within the capitalist logic of Brazilian society.

Keywords: Subject. Discourse. History. Event. 


\section{A mobilização do acontecimento}

Neste artigo, vamos problematizar as condições sócio-históricas de produção do discurso que levaram o sujeito, Organizações Globo, a declarar o "reconhecimento" do "erro" em ter apoiado e participado do Golpe Militar de 1964, no Brasil.

Belmira

Ao iniciarmos a presente introdução intitulando-a "A mobilizaMagalhães

Helson Flávio ção do acontecimento", estamos fazendo um movimento duplo. De início, teorizamos sobre a Análise do Discurso (AD) e, ao mesmo tempo, da Silva ressaltamos as "mobilizações de rua" que aconteceram recentemente Sobrinho no Brasil, nos últimos meses (entre maio e outubro de 2013) ${ }^{1}$. Assim sendo, estrutura e acontecimento se encontram/confrontam e o método marxiano permite constatar a impossibilidade de essas categorias funcionarem isoladamente.

Em nossa investigação, compreendemos que a interseção entre a estrutura que nos remete às relações de produção de determinada sociabilidade e a tomada de posição do sujeito discursivo que promove o acontecimento é um ponto crucial nos estudos sobre o discurso e só pode ser entendido no processo dialético entre objetividade e subjetividade, o qual constitui toda práxis humana.

\section{Condições de produção e sujeito no/do discurso}

No estudo sobre o discurso e o sujeito na/da práxis social (MAGALHÃES, 2013), é preciso destacar que as amplas Condições de Produção referemse, do ponto de vista do materialismo histórico-dialético, às relações de produção de determinado período histórico de uma sociabilidade. Ou seja, as condições de produção devem ser tomadas como fundantes de toda práxis humana. Por isso, ressaltamos que em uma sociabilidade capitalista, particularmente no período contemporâneo e atual ${ }^{2}$, todas as práxis sociais, inclusive as discursivas, serão afetadas pelas relações de classes geradas pela lógica capitalista.

Afirmar isso é dizer que a luta de classes historicamente se desenrola entre capitalistas e trabalhadores e que o antagonismo entre as classes desse sistema subsume todos os discursos contemporâneos.

\footnotetext{
1 Importante frisar que essa data é a da finalização deste artigo, mas novos fatos indicam a continuação das manifestações no Brasil.

2 Estamos nos referindo às teorias da pós-modernidade que afirmam a inexistência das lutas de classes na atualidade, transformando as contradições de classes em diferenças entre posições, ressaltando, assim, a inexistência de confronto de classes, havendo apenas disputas por melhores condições de vida.
} 
Como afirma Pêcheux (1988), “as contradições ideológicas que se desenvolvem através da unidade da língua são constituídas pelas relações contraditórias que mantêm, necessariamente, entre si os 'processos discursivos', na medida em que se inscrevem em relações ideológicas de classes" (p. 93).

No entanto, afirmar tal pressuposto sobre as condições de produção não basta para entender as práxis sociais, pois a condição do fazer humano na contemporaneidade, apesar de ter esse aspecto determinante, será sempre afetada pelas circunstâncias de outros complexos que formam a totalidade social (política, direito, arte, religião, ciência, moral etc.) e interferem na posição do sujeito, já que a subjetividade se constitui na relação com a objetividade. Como afirma Chasin (1990, p. 119):

"Erro" no apoio ao Golpe de 64

A subjetividade não é uma interioridade autônoma. Subjetividade é algo que se põe na medida em que se relaciona com a objetividade. Ela tem o poder de mudar a realidade, mas depende tanto no seu pôr e no seu captar da própria realidade. Ela não é autônoma. Ela é a subjetividade da realidade. É o mundo objetivo tornado interioridade.

Isso implica afirmar que ao materialismo histórico-dialético a categoria metodológica de totalidade é primordial para que se torne possível chegar ao real da história e à posição ideológica do sujeito do discurso; isto é, para que seja possível realizar a dialeticidade entre objetividade e subjetividade.

O discurso, como toda práxis humana, para ser explicado, segundo o método marxiano, necessita que o analista parta do fenomênico - da materialidade linguístico-discursiva -, pois é o fenomênico, em seu efeito de evidência, que, quando submetido à análise, pode nos levar a identificar a essência, permitindo, assim, chegar à totalidade do complexo sócio-histórico. Esta é entendida aqui como "um conjunto de partes, articuladas entre si, com uma determinada ordem e hierarquia, permeadas por contradições e mediações e em constante processo de efetivação" (TONET, 2013, p. 94).

A não compreensão dessa categoria levou a inúmeros equívocos no entendimento do método marxiano, porquanto a realidade foi considerada como impossível de ser explicada a partir da relação entre essência e aparência. A totalidade, do ponto de vista marxiano, não se re- 
fere a um total estático, senão a um caminho apresentado pelo próprio real para sua explicitação. Como diz ainda Tonet (2013, p. 95):

Totalidade, portanto, como princípio metodológico, significa que nada pode ser compreendido de modo isolado. $\mathrm{O}$ sentido de

Belmira

Magalhães

Helson Flávio

da Silva

Sobrinho

180

cada parte, de cada fato, de cada dado só emerge na medida em que ele for apreendido como momento de um conjunto, como resultado de um processo através do qual cada um dos elementos parciais vai adquirindo a sua natureza e a sua especificidade. Trata-se, pois, de apreender o processo através do qual vão se constituindo, ao mesmo tempo, a totalidade de determinado objeto e as partes que o compõem, a hierarquia e a ordem entre os diversos momentos, o modo como se relacionam entre si o todo e as partes, sob a regência do primeiro, as relações das diversas partes entre si e a passagem de um momento a outro.

Quando tomamos essa questão, o ponto que assinalamos é, sobretudo, a existência de uma relação dialética no complexo da totalidade; por isso, compreendemos que a essência, no caso da historicidade contemporânea, são as relações de produção capitalistas. O problema está em compreender que essa essência não é estática, mas histórica, por isso também contraditória, e sofrerá sempre a influência da posição ideológica do sujeito (formação ideológica) e da sua filiação às formações discursivas que determinam o que pode, como se pode e o que não se pode dizer em uma conjuntura histórica ${ }^{3}$.

Nesse sentido, quando analisamos o processo discursivo, é preciso levar em consideração que não nos é suficiente afirmar que em todos os discursos de hoje as relações capitalistas estão funcionando. É preciso, de fato, perceber e compreender como se dá esse funcionamento, como a posição do sujeito, nas formações ideológicas e discursivas, afeta dialeticamente a discursividade enquanto efeito e intervenção na história ${ }^{4}$. Esse trajeto permite chegar à explicação e elucidação do discurso em sua totalidade primeira e na relação com outras totalidades e assim compreender os efeitos de sentido que

3 Ver Pêcheux e Fuchs (1997).

4 "Tomamos a discursividade, por definição, como o lugar que nos permite observar os efeitos materiais da língua, enquanto sistema passível de jogo, na história. Resulta desse jogo que a produção de sentidos é marcada necessariamente pelo equívoco." (ORLANDI, 1996, p. 132). 
determinado discurso produz no real sócio-histórico. Segundo Silva Sobrinho,

\begin{abstract}
[...] é das contradições sócio-históricas que brota a natureza conservadora e/ou revolucionária/transformadora de todo discurso. No caso da sociabilidade capitalista, suas contradições são fundadas na propriedade privada, na divisão social e técnica do trabalho, na exploração dos homens pelos homens, na lógica fetichista da mercadoria que visa à reprodução do capital. É essa base material, em seus aspectos e mediações contraditórias, que gera e sustenta as classes sociais da conjuntura histórica atual e suas posições antagônicas em lutas (visíveis ou não) no complexo contraditório-desigual-subordinado das relações sociais de produção. (SILVA SOBRINHO, 2011, p. 27).
\end{abstract} "Erro" no apoio ao Golpe de 64

No caso particular deste artigo, as perguntas que se impõem para buscar as pistas na discursividade em sua relação com a concretude histórica são: como o texto circulou produzindo um efeito de "reconhecimento do erro" das Organizações Globo no "apoio aos militares"? Quais bases ideológico-discursivas constituem esses dizeres? Como ele ressignifica a posição do sujeito do discurso (Organizações Globo) e dos que foram afetados pelos dizeres desse "reconhecimento do erro"?

\title{
Desvelando o "erro": ditadura e democracia equivalentes?
}

Colocadas as condições determinantes da sociedade capitalista e inserindo a realidade brasileira nessas contradições, precisamos agora chegar às condições restritas em que o "reconhecimento do erro" das Organizações Globo se fez acontecimento "no ponto de encontro de uma atualidade e de uma memória" (PÊCHEUX, 2002, p. 17).

A primeira observação a ser considerada neste estudo é a de que, durante o período de manifestações populares (em junho de 2013, ou o inverno brasileiro), os repórteres da Rede Globo foram criticados "duramente" e algumas vezes impedidos do exercício da profissão (carros virados, equipamentos quebrados, por exemplo). Os gritos e cartazes dos manifestantes diziam que a emissora (Globo) está sempre contra e que, além disso, suas imagens serviam para prejudicar os manifestantes. Uma crítica tão contundente e tão direta vinda das ruas ainda não havia ocorrido na atualidade. E o sujeito do discurso afirma seu "erro", 
trazendo o interdiscurso que diz que contra fatos não há argumentos, repetindo a construção do dito popular, que fortalece o efeito de possível "arrependimento", ou seja, retomando memórias e trazendo-as para a atualidade, a fim de produzir determinados efeitos de sentido.

Nossa análise se encaminha para mostrar que contra fatos há argu-

Belmira

Magalhães

Helson Flávio da Silva

Sobrinho mentos, pois o funcionamento do discurso analisado nos evidencia que, embora haja um fato, o efeito de "arrependimento" pode ser modalizado, a depender do lugar que o sujeito ocupe nas relações sócio-históricas e ideológicas. Vejamos:

Desde as manifestações de junho, um coro voltou às ruas: 'A verdade é dura, a Globo apoiou a ditadura'. De fato, trata-se de uma verdade, e, também de fato, de uma verdade dura. (grifos nossos).

Esse recorte é das Organizações Globo e permite pensar sobre como a "escuta" desses ecos "incômodos" que se produziram na rua afetaram a emissora. Esta antecipou a divulgação da nota do "erro", "reconhecendo" que se trata, de fato, de uma "verdade $\leftrightarrow$ uma verdade dura". No entanto, a nosso ver, esse fato isolado não é o responsável pelo abalo que sofreu a grande mídia, em especial o complexo das Organizações Globo, objeto desta análise, durante as manifestações de junho. Sabemos com Orlandi que

\footnotetext{
A mídia é um grande evento discursivo do modo de circulação da linguagem. Enquanto tal, ela é um acontecimento de linguagem que impõe sua forma de gerenciamento dos gestos de interpretação, sempre na distinção do que se deve apreender como sentido unívoco (literal) e o que admite plurivocidade interpretativa. Com a mídia há uma organização do trabalho intelectual e uma nova divisão do trabalho da leitura. (1996, p. 96).
}

Foi justamente esse "gerenciamento dos gestos de interpretação" que ficou exposto nas contradições dos sentidos emergentes e "incômodos". Na luta de forças pela divisão de leitura/interpretação dos fatos, compreendemos também que a grande mudança, que se fez acontecimento nessa materialidade discursiva e perturbou o aparato midiático, foi a impossibilidade de sustentação do discurso de neutralidade jornalística pela posição da imprensa que dizia estar apenas registrando 
e noticiando os fatos. Afirmações, imagens, entrevistas que antes eram tidas como a expressão da "verdade", do "fato em si", tão alardeadas no principal jornal televisivo da emissora, foram questionadas pelo grande número de fotos, vídeos, postagens que circularam nas redes sociais e se multiplicaram exponencialmente.

O posicionamento da Rede Globo contra as manifestações foi enfático nas primeiras reportagens sobre as manifestações de rua. Mas, com as confrontações das redes sociais, o sujeito Organizações Globo faz deslizar sentidos e, em mais um gesto de interpretação, passa a enaltecer as "manifestações pacíficas", uma vez que circulavam dizeres como "O Gigante acordou". À medida que cresce o discurso da "manifestação pacífica", as filiações identificadoras de valores burgueses "democráticos" crescem, separando (dividindo) os "manifestantes"; passa, então, "Erro" no apoio ao Golpe de 64 a imprensa a condenar veementemente os "baderneiros". As práticas e conflitos ideológicos deixam exposto o gesto ideológico do jornalismo ao produzir notícia, e isso se mostrou contundentemente com as idas e vindas de lugares discursivos diversos, implicando, por exemplo, que os sujeitos "na rua" fossem classificados como "vândalos", que passou a ser o antônimo de "pacíficos".

Percebemos o acirramento das críticas às Organizações Globo e, paralelamente, o deslizamento da posição sujeito que condena as manifestações para a posição que as aprova e, ao mesmo tempo, condena os "vândalos", criando uma nova forma de noticiar: Protesto $\leftrightarrow$ Manifestação pacífica versus Baderna $\leftrightarrow$ Manifestação de vândalos.

Esse tipo de abordagem é utilizado pela mídia como forma de "classificar" os movimentos criando rótulos negativos, produzindo um efeito de condenação dos movimentos. Contra o MST essa prática tem sido utilizada sempre:

\footnotetext{
Do modo como narra a trajetória do MST, a imprensa revela sua posição nos conflitos sociais. Os 'pobres' (sem-terra) passam a ser 'invasores', ‘criminosos' e ‘baderneiros'. [...] É com essa reprodução da informação que a imprensa vai formando a opinião do leitor contra as reivindicações dos trabalhadores do campo, construindo discursivamente sentidos que tornam o MST um Movimento cujo objetivo é 'simplesmente' fomentar a 'desordem'. (MAGALHÃES; SILVA SOBRINHO, 2010, p. 47).
} 
$\mathrm{Na}$ análise, podemos constatar que a imprensa produz uma discursividade que é constituída sempre a partir do mesmo "refrão": as manifestações começam "pacíficas" e terminam em "badernas". Como diz Orlandi (1999, p. 38): “O sujeito (e os sentidos), pela repetição, estão sempre tangenciando o novo, o possível, o diferente. Entre o efêmero e Belmira o que eternaliza. Num espaço fortemente regido pela simbolização do Magalhães poder." Assim é que se conclui que os "vândalos" prejudicam as conquistas dos "cidadãos brasileiros" que vivem num país tido como demo-

Helson Flávio da Silva Sobrinho crático e livre. Paradoxalmente, a repressão torna-se necessária pelas armas (balas de borrachas, bombas de efeito moral) para a manutenção do poder das elites ${ }^{5}$.

As reportagens criam, a partir do efeito de repetição, um perigo iminente que sugere o afastamento dos "cidadãos de bem" da rua, espaço de "luta" e "conflito". Ou seja, subentende-se que há uma condenação ao ativismo radical, pois o outro se tolera, mas bom mesmo seria que ele não existisse, pois as mudanças desejadas pelo "povo" são tidas como ameaça aos donos do poder, devido ao risco de levarem à perda de privilégios da elite.

É necessário ainda apresentar como foi construído discursivamente pelo jornal o Globo o apoio ao Golpe de 64, há quase meio século. As sequências discursivas selecionadas a seguir mostram a forma de adesão à tomada do poder político no Brasil pelos militares:

\section{$\operatorname{Em} 2 / 4 / 1964$}

- Fugiu Goulart, e a democracia está sendo restaurada.

- Salvos da comunização que celeramente se preparava, os brasileiros devem agradecer aos bravos militares que os protegeram de seus inimigos.

Em 4/4/1964

- A revolução democrática antecedeu em um mês a revolução comunista.

Essas sequências não aparecem quando o discurso do efeito de "arrependimento" é publicado, fazendo com que o "erro" seja suavizado, pois a veemência do "apoio" não se faz presente nessa retomada da memória. No entanto, está presente, de fato, no momento do golpe (31

5 Não vamos tratar aqui da forma como foram denunciadas as "armações policiais para colocar os manifestantes no lugar de vândalos". 
de março de 1964) a decisão de aderir aos não trabalhadores, considerados inimigos pelo jornal, pois eles é que estavam se manifestando e criando problemas para o jornal, que, como nos informa no discurso do "erro", não pôde circular "em 1/4/1964 por ter sido invadido por fuzileiros navais, do dispositivo militar de Jango". Vemos que o jornal que "apoia" o golpe estava sendo pressionado pelo poder vigente.

Postas as condições em que se dá a nota de "reconhecimento do "erro" das Organizações Globo pelo seu "apoio" ao Golpe de 1964 no Brasil e participação nele, passemos agora, com maior aprofundamento, à materialidade discursiva publicizada no site institucional memória. oglobo, em que encontramos "A História do jornal o Globo desde a sua fundação". Nele podemos visualizar uma janela intitulada "erros e acusações falsas", sob o seguinte título:

"Erro" no

apoio ao

Golpe de 64

31 DE MARÇO DE 1964

Apoio ao golpe de 64 foi um erro 6

Ao visualizar esse enunciado, estamos nos deparando com um discurso que se pretende transparente, límpido. No entanto, essa composição do enunciado nos exige desconfiar do óbvio: o que se diz? Como se diz? E o que não se diz? Para quem se diz? Por isso, é preciso retomar Orlandi quando problematiza as formas do silêncio e nos esclarece que

\footnotetext{
Se diz ' $x$ ' para não (deixar) dizer ' $y$ ', este sendo o sentido a se descartar do dito. É o não-dito necessariamente excluído. Por aí se apagam os sentidos que se quer evitar, sentidos que poderiam instalar o trabalho significativo de uma 'outra' formação discursiva, uma 'outra' região de sentidos. O silêncio trabalha assim os limites das formações discursivas, determinando consequentemente os limites do dizer. (ORLANDI, 2002, p. 76).
}

Nesse aspecto, no momento histórico atual, não é possível mais silenciar sobre o acontecimento passado, memória histórica. No entanto, o discurso tece linhas de tentativas para explicar que a adesão ao Golpe de 1964 foi um "erro", mas que hoje isso pode ser perfeitamente entendido

6 Disponível em: <http://memoria.oglobo.globo.com/erros-e-acusacoes-falsas/apoio-ao-golpe-de64-foi-um-erro-9328244>. Acesso em: 30 set. 2013. 
pelas circunstâncias da época, que induziam ao "equívoco". Assim, o discurso do sujeito se inscreve em uma região do dizível para falar, apagando, imaginariamente, as contradições que estão ali constituindo o dizer.

Em outro trecho do texto do jornal, podemos verificar as estratégias argumentativas montadas para a confissão do "erro":

Belmira

Magalhães

Helson Flávio

da Silva

Sobrinho

186

Já há muitos anos, em discussões internas, as Organizações Globo reconhecem que, à luz da História, esse apoio foi um erro.

Há alguns meses, quando o Memória estava sendo estruturado, decidiuse que ele seria uma excelente oportunidade para tornar pública essa avaliação interna. E um texto com o reconhecimento desse erro foi escrito para ser publicado quando o site ficasse pronto.

Não lamentamos que essa publicação não tenha vindo antes da onda de manifestações, como teria sido possível. Porque as ruas nos deram ainda mais certeza de que a avaliação que se fazia internamente era correta e o reconhecimento do erro, necessário.

Governos e instituições têm, de alguma forma, que responder ao clamor das ruas.

Comecemos a análise pelas chamadas sobre o tempo. A expressão "já há muitos anos", que inicia a sequência discursiva, produz no leitor um efeito de passado longínquo, de histórias de outras épocas. Em contraponto, temos que "há alguns anos" resolveu-se publicar o "reconhecimento do erro", produzindo um efeito de "arrependimento". No entanto, a construção se dá através do efeito de afastamento dos fatos, daqueles fatos que insistem em significar, condenando as Organizações Globo pelo apoio ao Golpe de 1964, mas que são possíveis de ser amenizados pelo afastamento do tempo em que ocorreram. Os que escrevem e divulgam o texto não foram, em sua maioria, os que cometeram o "erro", mas mesmo assim resolveram se justificar: passado e presente são completamente diferentes; lá (ontem), ditadura; aqui (hoje), democracia.

Ingressar nessa análise nos possibilita também pensar sobre a relação memória e esquecimento, pois esse acontecimento é "reconhecido", "avaliado" e "justificado" à luz da História, portanto implica novamente num efeito de "verdade", porquanto diz "responder ao clamor das ruas". Do ponto de vista discursivo, esses dizeres retomam um discurso de condenação ("a verdade é dura") para produzir outros sentidos, reafirmando um compromisso social, ou com o social, de "Go- 
vernos e instituições", ou seja, compromisso das esferas públicas e privadas unidas na resposta pela manutenção do poder. Por isso, no outro recorte da materialidade discursiva, podemos também visualizar que são trazidos para a cena enunciativa, "de apoio", outros jornais, com o intuito de se fazer acompanhar também por outros grandes órgãos de imprensa no "apoio" dado aos militares.

A lembrança é sempre um incômodo para o jornal, mas não há como refutá-la. É História. O GLOBO, de fato, à época, concordou com a intervenção dos militares, ao lado de outros grandes jornais, como 'O Estado de S. Paulo', 'Folha de S. Paulo', 'Jornal do Brasil' e o ‘Correio da Manhã', para citar apenas alguns. Fez o mesmo parcela importante da população, um apoio expresso em manifestações e passeatas organizadas em Rio, São "Erro" no apoio ao Golpe de 64

Naqueles instantes, justificavam a intervenção dos militares pelo temor de um outro golpe, a ser desfechado pelo presidente João Goulart, com amplo apoio de sindicatos - Jango era criticado por tentar instalar uma 'república sindical' - e de alguns segmentos das Forças Armadas.

Na noite de 31 de março de 1964, por sinal, o GLOBO foi invadido por fuzileiros navais comandados pelo Almirante Cândido Aragão, do 'dispositivo militar' de Jango, como se dizia na época. O jornal não pôde circular em $1^{\circ}$ de abril. Sairia no dia seguinte, 2, quinta-feira, com o editorial impedido de ser impresso pelo almirante, 'A decisão da Pátria'.

Novamente encontramos sentidos paradoxais, pois lemos "lembrança incômoda para o jornal” -, "mas não há como refutá-la. É História”. Ou seja, “tocamos aqui um dos pontos de encontro com a questão da memória como estruturação de materialidade discursiva complexa, estendida em uma dialética da repetição e da regularização" (PÊCHEUX, 1999, p. 52). Desse modo, podemos compreender que se trata de uma forma determinada de retorno a uma memória que não se apaga, e por isso "incomoda", mas que pode ser retomada "à luz da História" para ser lida, “justificada", "explicada”, dando ao sujeito-leitor a impressão de um acordo, aparentemente intersubjetivo, entre os sujeitos na produção desses sentidos, por causa da "ameaça", do "temor" a uma possível "república sindical". Ou seja, o efeito ideológico do já-dito está ali sustentando o dizer. 
Como já mencionado, diante da situação criada pelas manifestações de rua, o discurso traz uma justificativa de que o outro golpe seria pior. Pior por quê? Pior para quem? Simplifica-se a história para torná-la aliada do "arrependimento" possível.

Esses recortes das materialidades discursivas já nos parecem

Belmira

Magalhães

Helson Flávio

da Silva

Sobrinho

188

[...] o fato é que o uso da palavra 'comunismo' nos jornais, ao longo dos anos, para além de designar uma ideologia partidária, passou a determinar um sentido que, como já mencionamos, é sempre negativo. Hegemonicamente, a produção de sentidos para 'comunista' gira em torno de 'inimigo', o outro indesejável. Se o lugar de inimigo está previamente assinalado no imaginário social, significar o comunismo e os comunistas deste modo possibilita torná-los visíveis, singularizá-los e, assim, deixá-los isolados e sob controle, como todo inimigo deve ficar.

Assim, o outro "golpe", referido pelo jornal, seria pior, pois implicaria tirar o poder do sujeito discursivo dominante dessa sociedade. Mais uma vez nos deparamos com a interpretação, afetada pelo ideológico, tomando a realidade como evidência natural.

Seja como for, há sempre interpretação, ou seja, tomadas de posição nos conflitos sociais. Por isso, podemos ainda visualizar na continuação do discurso a argumentação explícita do poder que essa organização passou a possuir ao apoiar o Golpe de 1964. O próprio sujeito discursivo, na tentativa de salvar a imagem do dono do jornal, explicita seu poder e a participação direta nas decisões sobre as prisões na ditadura.

Durante a ditadura de 1964, sempre se posicionou com firmeza contra a perseguição a jornalistas de esquerda: como é notório, fez questão de abrigar muitos deles na redação de O GLOBO. São muitos e conhecidos os depoimentos que dão conta de que ele fazia questão de acompanhar 
funcionários de O GLOBO chamados a depor: acompanhava-os pessoalmente para evitar que desaparecessem. Instado algumas vezes a dar a lista dos 'comunistas' que trabalhavam no jornal, sempre se negou, de maneira desafiadora.

Ficou famosa a sua frase ao general Juracy Magalhães, ministro da Justiça do presidente Castello Branco: 'Cuide de seus comunistas, que eu cuido dos meus.'

Assim, podemos constatar que sujeito e sentidos se constituem simultaneamente, como diz Orlandi (1996, p. 56): “Ao produzir sentido, o sujeito se produz, ou melhor, o sujeito se produz, produzindo sentido. É esta a dimensão histórica do sujeito - seu acontecimen"Erro" no apoio ao Golpe de 64 to simbólico -, já que não há sentido possível sem história, pois é a história que provê a linguagem de sentido, ou melhor, de sentidos." Não por ingenuidade, aparece no texto "seus/meus comunistas" como forma de o poder significar o outro e diferenciar, separar sujeitos, controlar, eliminar. A reprodução desse sentido institucionalizado faz aparecer o processo de constituição da posição sujeito do jornal, pois a história intervém e se inscreve na língua, visto que "acompanhava-os pessoalmente para evitar que desaparecessem", desvelando nesse efeito metafórico de desaparecimento o poder do Estado, das classes dominantes, sobre vida e morte de determinados sujeitos. Segundo Indursky (1997, p. 260):

[...] o Golpe de Estado de 1964 apresentou como pretexto o propósito de salvar a pátria da corrupção, da desordem, do desmando e do comunismo. Com tais propósitos empolgaram o poder, nele perpetuando-se até março de 1985. Durante esse período, impuseram suas posições e calaram as vozes discordantes. Esse período caracterizou-se, pois, pelo arbítrio e pela falta de liberdade de expressão, marcas de um discurso autoritário.

Podemos aprofundar ainda esta análise citando Pêcheux (2002, p. 53): “Todo enunciado, toda sequência de enunciados é, pois, linguisticamente descritível como uma série (léxico-sintaticamente determinada) de pontos de deriva possíveis, oferecendo lugar à interpretação". De fato, pode-se ver como o discurso se dirige aos poderosos, aos donos da 
“democracia”. Por isso, esse léxico, "democracia”, é repetido insistentemente no texto do Jornal, "Apoio ao golpe de 64 foi um erro".

'Ressurge a Democracia'

Belmira

Naquele contexto, o golpe, chamado de 'Revolução', termo adotado por $\mathrm{O}$

Magalhães

Helson Flávio

da Silva

Sobrinho GLOBO durante muito tempo, era visto pelo jornal como a única alternativa para manter no Brasil uma democracia.

Destacava também os avanços econômicos obtidos naqueles vinte anos, mas, ao justificar sua adesão aos militares em 1964, deixava clara a sua crença de que a intervenção fora imprescindivel para a manutenção da democracia e, depois, para conter a irrupção da guerrilha urbana.

A democracia é um valor absoluto. E, quando em risco, ela só pode ser salva por si mesma. (grifos nossos).

Essa deriva do discurso mostra as filiações identificadoras entre “golpe $\leftrightarrow$ 'Revolução’ $\leftrightarrow$ democracia”. Trata-se de filiações históricas organizadas e desorganizadas em memórias de interesses sociais dominantes que fazem aceitar e "justificar" que nessa luta político-ideológica não havia alternativa.

Essa ausência/presença da raiz dos conflitos da sociedade capitalista na materialidade discursiva, em nome da "democracia como valor absoluto" - consenso -, estabelece relações de sentidos determinadas em sua historicidade e, por isso, fez e faz política, violência, censura, morte etc., para salvaguardar a "democracia" de um Estado nacional, mesmo que praticado sob o efeito de muito silêncio e de muita violência institucional.

\section{Considerações que sugerem um final}

Ao analisar essa materialidade discursiva, compreendemos que as Organizações Globo não pedem desculpas, pois "de fato" não se "arrependem"; ao contrário, se "justificam" pelo "reconhecimento" do “erro", do "equívoco", do "desacerto". Essa recorrência do dizer é para nós, analistas, um gesto de interpretação da e na História, a revelar "os momentos de interpretações enquanto atos que surgem como tomadas de posição, reconhecidas como tais, isto é, como efeitos de identificação assumidos e não negados" (PÊCHEUX, 2002, p. 57, grifo nosso). 
Certamente, essa também é a clareza das Organizações Globo, que, ao lançarem seu "reconhecimento do erro", reafirmam sua prática, não negando sua posição na sociedade brasileira.

Esse efeito de transparência no retorno à memória produz um jogo discursivo de interesse capitalista que se manifesta no discurso político do "apartidarismo" de hoje. Estamos pensando, aqui, em como o discurso permite que a persona do Capital (MÉSZÁROS, 2002) se apresente com diferentes máscaras "sem partido", para afirmar que o mais importante são os objetivos perseguidos para a consolidação da lógica do capital, agora politicamente revestida de democracia (leia-se: "manutenção" da lógica do capital). Essa é a "marca do real histórico" nessa discursividade.

O desdobramento dessa posição em não dar apoio a determinado partido em detrimento de outro implica um "acerto" das classes domi-

"Erro" no apoio ao Golpe de 64

\section{Referências}

CHASIN, José. Sobre o liberalismo. Maceió, 1990. Mimeografado.

INDURSKY, Freda. A fala dos quartéis e as outras vozes. Campinas: Ed. da Unicamp, 1997.

MAGALHÃES, Belmira; SILVA SOBRINHO, Helson. O efeito ideológico de deslocamento no discurso da imprensa sobre o MST: de pobres da terra a baderneiros. Revista Veredas [on-line], Juiz de Fora: PPG-Linguística/UFJF, v. 15, n. 2, 2010. Disponível em: <http:// www.ufjf.br/revistaveredas/edicao-atual/>. Acesso em: 15 set. 2013.

Sujeito no e do discurso: pensando a resistência. In: PETRI, Verli; DIAS, Cristiane. Análise de discurso em perspectiva: teoria, método e análise. Santa Maria: Ed. da UFSM, 2013. p. 203-217. 
MARIANI, Bethânia. O PCB e a imprensa: os comunistas no imaginário dos jornais (1922-1989). Rio de Janeiro: Revan; Campinas: Ed. da Unicamp, 1998.

MÉSZÁROS, István. Para além do capital. Campinas: Boitempo, 2002. Belmira

Magalhães ORLANDI, Eni. As formas do silêncio no movimento dos sentidos. 5. ed. Campinas: Ed. da Unicamp, 2002.

Helson Flávio

da Silva . Interpretação. Petrópolis: Vozes, 1996.

Sobrinho

Análise de discurso: princípios e procedimentos. Campinas: Pontes, 1999.

PÊCHEUX, Michel. O discurso: estrutura ou acontecimento. 3. ed. Campinas: Pontes, 2002.

Papel da memória. In: ACHARD, Pierre et al. Papel da memória. Campinas: Pontes, 1999. p. 49-57.

Semântica e discurso: uma crítica à afirmação do óbvio. Campinas: Ed. da Unicamp, 1988.

; FUCHS, C. A propósito da análise automática do discurso: atualização e perspectivas (1975). In: GADET, Françoise; HAK, Tony (Org.). Por uma análise automática do discurso: uma introdução à obra de Michel Pêcheux. 3. ed. Campinas: Ed. da Unicamp, 1997. p. 163-252.

SILVA SOBRINHO, Helson. Análise do Discurso e a insuportável luta de classes na teoria e na prática. In: TFOUNI, Leda Verdiani et al. (Org.). A análise do discurso e suas interfaces. São Carlos: Pedro \& João Editores, 2011. p. 17-40.

TONET, Ivo. Método científico: uma abordagem ontológica. São Paulo: Instituto Lukács, 2013. 